\title{
Ixodid ticks on wild donkeys in a Mediterranean nature reserve (Asinara National Park): diversity and risk factors
}

\author{
S. A. Z A N Z A N I ${ }^{1}$, E. P I N T O R E ${ }^{2}$, E. O L I V I E R I ${ }^{1}, \mathrm{~N}$. C O L U M B A N O ${ }^{2}$, \\ A. S C A N U2, V. MEL O S U², E. SA N N A A S S I O ${ }^{2}$, G. CA R E D U ${ }^{3}$, \\ A. L. GAZZONIS ${ }^{1}$, M. T. M A N F R D I ${ }^{1}$ and G. G A R I P P A ${ }^{2}$ \\ ${ }^{1}$ Department of Veterinary Medicine (DIMEVET), Università degli Studi di Milano, Milan, Italy, ${ }^{2}$ Department of Veterinary \\ Medicine (DIMEVET), Università di Sassari, Sassari, Italy and ${ }^{3}$ Parco Nazionale dell’ Asinara, Sassari, Italy
}

\begin{abstract}
The Sardinian coloured donkey Equus asinus (Perissodactyla: Equidae) and its albino colour morph represent the wildlife species most typical of the island of Asinara. This Mediterranean island represents a favourable context for ticks and tick-borne diseases; however, knowledge of the tick fauna on Asinara is scarce. A total of 106 Sardinian donkeys were inspected for tick infestation from June to November 2015. All ticks found were collected, classified by stage and sex, and identified to species level. The level of infestation of each donkey was determined; both the overall tick infestation and infestations of each detected species were classified on a scale of 1-3 to give an infestation score (IS). Overall, 256 hard ticks were collected from 60 of 106 donkeys (56.6\%). Rhipicephalus bursa, Haemaphysalis punctata and Hyalomma marginatum (all: Ixodida: Ixodidae) infested $26.4 \%, 28.3 \%$ and $6.6 \%$ of donkeys, respectively. Different variables affected the IS. With reference to overall tick infestation, a higher IS was observed in donkeys grazing on grassland and Mediterranean shrubland and in albino donkeys compared with coloured donkeys. The collected ticks included species involved in the transmission of pathogens to humans, which highlights the risks for public health in a tourist destination such as Asinara National Park.
\end{abstract}

Key words. Equus asinus, Haemaphysalis punctata, Hyalomma marginatum, Rhipicephalus bursa, hard tick, parasites, Asinara Island.

\section{Introduction}

Ixodid ticks are blood-feeding arthropods with a worldwide distribution. They are the most effective vectors of a wide variety of pathogens that cause diseases in humans and animals. Ticks are also associated with irritation, painful wounds, tick bite allergies, blood loss, tick paralysis and severe toxic conditions (Sonenshine, 1993; Guglielmone et al., 2014).

In nature, tick fauna and the maintenance of tick-borne pathogens depend mainly on environmental conditions, vegetation and host availability (Pfäffle et al., 2013; Otranto et al., 2014). Only approximately $10 \%$ of ticks feed on domesticated animals because they are primarily parasites of wild animals, and their hosts' behaviour seems to be an essential factor in the distribution and dispersal of ticks (Estrada-Peña, 2001; McCoy etal., 2001), which have only limited independent movement. Natural zones with high densities of ticks are considered to pose higher levels of risk for disease not only to animals but also to humans because ixodids are often indiscriminate in their choice of hosts and hence many may feed opportunistically on humans. In addition, ticks also reduce the recreational value of many parks, campsites and hiking paths (Olivieri et al., 2017).

Asinara $\left(41^{\circ} 03^{\prime} 28^{\prime \prime} \mathrm{N}, 08^{\circ} 16^{\prime} 33^{\prime \prime} \mathrm{E}\right)$ is an island in the Mediterranean Sea, located to the northwest of Sardinia, Italy. 


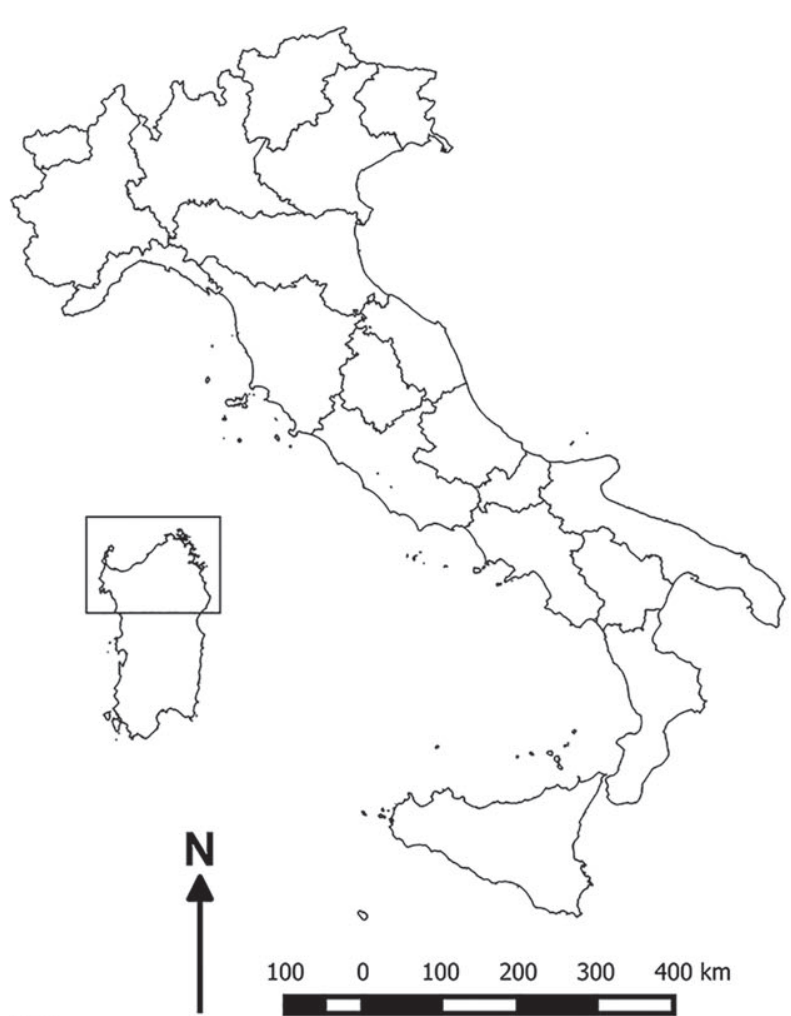

(A)

Fig. 1. Study area (A, B) showing the three regions of the island of Asinara (Asinara National Park) where ticks were collected and (C) sites of sampling of donkeys $(\bullet)$.

The island was inhabited until 1885, at which time it was closed and the population transferred as the island was used as a quarantine facility and subsequently a high-security prison colony. The island was opened to the public in 1999 following the formation of Asinara National Park. At present, the island is permanently inhabited by only two residents, a marshal and a sculptor. Another few dozens of workers (e.g. people employed in tourism, forest rangers, researchers) populate Asinara National Park discontinuously throughout the year. The island covers an area of $50.9 \mathrm{~km}^{2}$; its width is highly variable and ranges from $290 \mathrm{~m}$ at the narrowest point to $7 \mathrm{~km}$ at the widest. The island is mainly hilly and peaks in altitude in the northern part ( $408 \mathrm{~m}$ a.s.1.). The few flat areas stretch between the coast and the hilly areas, mainly in the southern and northern regions. The island's climate is typical of the Mediterranean region, with mild winters and hot, dry summers. The average temperature of the coldest month, February, is $10.8^{\circ} \mathrm{C}$ and that of the hottest month, August, is $23.3^{\circ} \mathrm{C}$. Rainfall is very scarce and reaches an average of $481 \mathrm{~mm}$ per year.

The island is characterized by several vegetal communities and abundant wildlife. A forest grows on metamorphic rocks in the northern part of the island and micro-forests are observed in the southern part. Mediterranean shrubland is common on schist and granite rocks. Perennial and annual herbaceous species occur diffusely in grasslands. Areas covered by sparse vegetation, that are often subject to fire, are less species-rich.

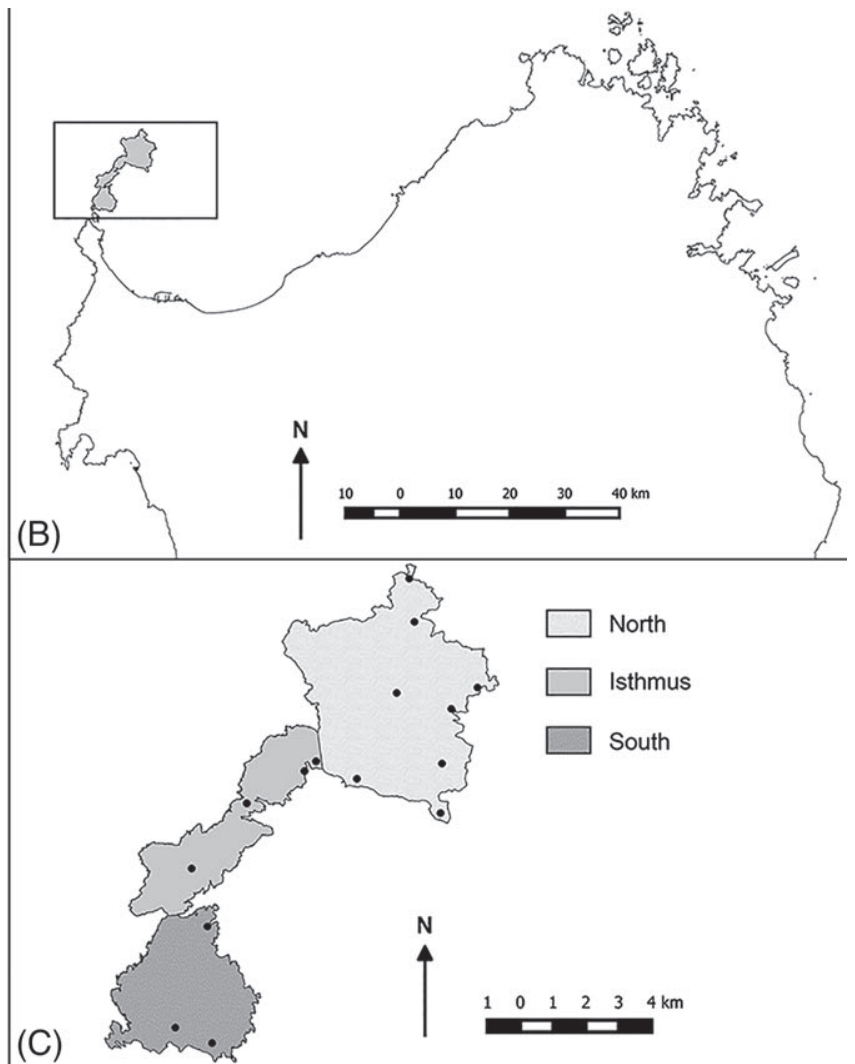
Y

The species most representative of the wildlife on Asinara island is the Sardinian coloured donkey (Equus asinus) and its albino colour morph. These represent some of the few wild equids still living in Europe (Kugler et al., 2008). The Food and Agriculture Organization, in accordance with the register of equine and asinine Italian local breeds, classified the albino donkey as a breed of critical status with a strong risk for extinction (Scherf, 2000; Ministero delle Politiche Agricole, Alimentari e Forestali, 2013). Both donkey types live in stable groups that graze and rest together in different areas of the island. A few other species of domestic and wild ungulate are present on the island, including Equus ferus caballus (Perissodactyla: Equidae), Capra hircus (Artiodactyla: Bovidae), Sus scrofa meridionalis (Artiodactyla: Suidae) and Ovis gmelini musimon (Artiodactyla: Bovidae).

Because of its use as a high-security prison in the last century, Asinara today represents one of the largest of the Mediterranean islands that have been minimally exploited in terms of land use. As a result, the island has been little affected by human activity for many years; in this context, important factors (climatic and environmental features, wild animals) may promote both the presence of many species of hard tick and the circulation of pathogens they transmit.

Previously, knowledge about the tick fauna of Asinara island has been scarce. The last contribution of Pinna et al. (1996) provided information on species occurring on the island on 

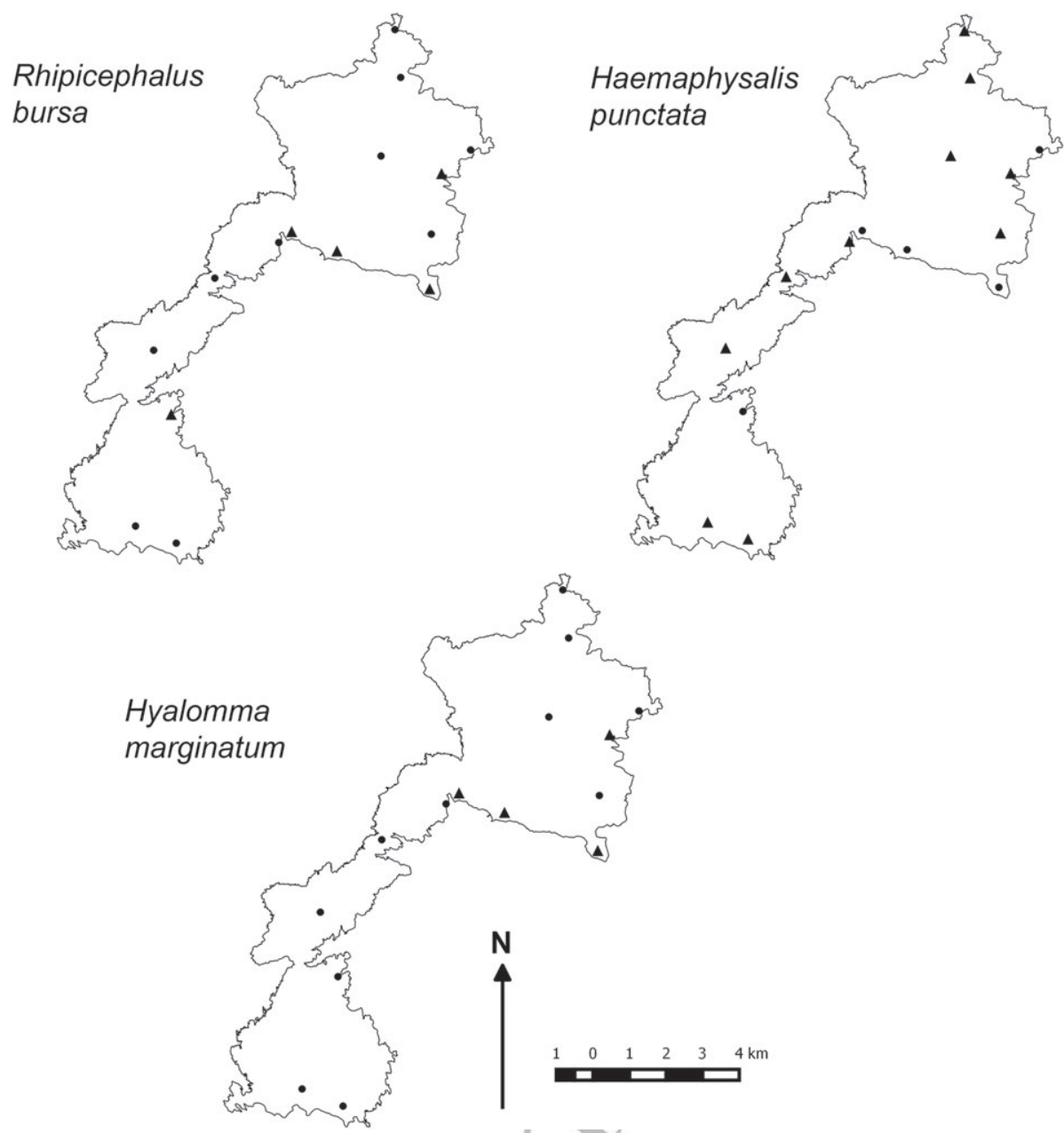

Fig. 2. Distribution of positive donkey herds in Asinara National Park by species of tick. $\mathbf{\Lambda}$, positive sampling site; $\bullet$, negative sampling site.

different hosts. Therefore, the present data about Asinara tick. fauna constitute an update. Here, the present authors report a study carried out in 2015 in Asinara donkeys with the primary aim of assessing the species and abundances of ticks infesting these donkeys. Furthermore, in order to determine the level of risk for tick bites and the transmission of tick-borne pathogens to the health of both donkeys and humans, variations in tick fauna according to space, vegetation cover and time of sampling are described and risk factors related to donkeys (donkey morph, individual features) and sampling (time, site, vegetation cover) are evaluated.

\section{Materials and methods}

From June to November 2015, as part of a study of the genetics of the donkeys living on Asinara island, a total of 106 donkeys (38 albino and 68 coloured) belonging to 15 different stable herds sited in the isthmus and the northern and southern parts of Asinara island were inspected for tick infestation (Fig. 1). In other months of the year, the island was closed to visitors and sampling was not carried out. Donkeys were of all ages (from
4 months to 25 years) and both sexes; they grazed in different sites, characterized by three types of land cover: sparse vegetation; Mediterranean shrubland, and grassland. The donkeys were captured using tele-anaesthesia (87 donkeys) or ropes and physical handling (19 donkeys) prior to the collection of ticks. The study was approved by the appropriate committees of both Asinara National Park and the University of Sassari. The skin of each donkey was inspected for the presence of ticks. In particular, preferred feeding sites, such as the head and ears, sternum, ventral abdominal region, inguinal region, perineal region and the base of the tail, were thoroughly checked. All detected ticks were collected, preserved in $70 \%$ ethyl alcohol and classified by stage of development and sex. Then, they were identified to species level under a stereomicroscope and a light microscope according to their morphological characteristics using specific keys (Manilla, 1998). The tick infestation level of each donkey was determined for both overall tick infestation and for each detected species and classified using an infestation score (IS) on a scale of 1-3. Donkeys with no ticks, those infested with one to 10 ticks and those infested with more than 10 ticks were given scores of 1, 2 and 3, respectively. The IS was introduced as a dependent variable in generalized linear models (GLMs) with 
Table 1. Species and prevalences of ticks collected on donkeys in Asinara National Park.

\begin{tabular}{lll}
\hline Tick species & $\begin{array}{l}\text { Donkeys } \\
\text { infested/examined, } n\end{array}$ & $\begin{array}{l}\text { Prevalence, } \\
\%\end{array}$ \\
\hline Rhipicephalus bursa & $23 / 106$ & $21.7 \%$ \\
Haemaphysalis punctata & $30 / 106$ & $28.3 \%$ \\
Hyalomma marginatum & $2 / 106$ & $1.9 \%$ \\
R. bursa and H. marginatum & $5 / 106$ & $4.7 \%$ \\
No ticks & $46 / 106$ & $43.4 \%$ \\
\hline
\end{tabular}

ordinal logistic regression. In each model, the following independent variables were introduced: date of sampling; location of sampling (north, south or isthmus); land cover type at the site of grazing (sparse vegetation, Mediterranean shrubland or grassland); donkey age (months); wither height (cm); body weight $(\mathrm{kg})$; sex, and coat (albino or coloured). Continuous variables were tested for multicollinearity. The components of the final multivariate model (GLM) were determined by backward elimination until all remaining variables were significant $(P<0.05)$. Statistical analyses were carried out using IBM sPSs Statistics for Windows Version 20.0 (IBM Corp., Armonk, NY, U.S.A.).

\section{Results}

Overall, 256 hard ticks (111 Rhipicephalus bursa, 133 Haemaphysalis punctata, 12 Hyalomma marginatum) were collected from 60 of 106 donkeys (prevalence of infestation: 56.6\%). Rhipicephalus bursa, H. punctata and Hy. marginatum infested $26.4 \%, 28.3 \%$ and $6.6 \%$ of donkeys, respectively; infested donkeys were found in 14 of the 15 stable groups. The spatial distribution of the positive herds is shown in Fig. 2. Monospecific infestations were observed in 55 of 60 donkeys (Table 1). The collected ticks were mainly adults $(77.3 \%)$; nymphs and larvae were classified exclusively as $H$. punctata (Table 2).

In the risk factor analysis, the final models after backward elimination showed that different variables affected the IS values for overall tick infestation and $R$. bursa and $H$. punctata infestations (Table 3 ). With regard to overall tick infestation, a higher IS was observed in donkeys grazing on grassland [odds ratio $(\mathrm{OR})=5.765,95 \%$ confidence interval $(\mathrm{CI}) 2.041-16.278$; $P<0.01]$ and Mediterranean brushland $(\mathrm{OR}=2.605,95 \% \mathrm{CI}$ $1.088-6.241 ; P<0.05)$ compared with those grazing on land covered by sparse vegetation (Fig. 3). Autochthonous albino donkeys presented a higher IS $(\mathrm{OR}=3.236,95 \% \mathrm{CI}$ 1.405-7.451; $P<0.01)$ than coloured Sardinian donkeys (Fig. 4). All of the other individual variables (age, wither height, body weight, sex) introduced in the GLM produced non-significant results; the same-was observed for location (north, isthmus, south) and date of sampling. Infested donkeys were found throughout the territory of Asinara island and throughout the study period (Fig. 5A). Rhipicephalus bursa IS was related to the date of sampling: both the prevalence and level of infestation in donkeys were higher in June and July than in October and November (Fig. 5B). With regard to individual features, the risk for a higher $R$. bursa IS increased in older animals $(\mathrm{OR}=1.009,95 \%$ CI $1.002-1.016 ; P<0.05)$.
Table 2. Tick species collected on donkeys in Asinara National Park stratified by tick stage.

\begin{tabular}{|c|c|c|c|c|c|c|}
\hline \multirow[b]{2}{*}{ Tick species } & \multicolumn{2}{|l|}{ Adults } & \multirow[t]{2}{*}{ Nymphs } & \multirow[t]{2}{*}{ Larvae } & \multicolumn{2}{|c|}{ Total } \\
\hline & $\begin{array}{l}\text { Males } \\
n\end{array}$ & $\begin{array}{l}\text { Females } \\
n\end{array}$ & & & $n$ & $\%$ \\
\hline $\begin{array}{l}\text { Rhipicephalus } \\
\quad \text { bursa }\end{array}$ & 57 & 54 & 0 & 0 & 111 & $43.4 \%$ \\
\hline $\begin{array}{l}\text { Haemaphysalis } \\
\text { punctata }\end{array}$ & 19 & 56 & 31 & 27 & 133 & $52.0 \%$ \\
\hline $\begin{array}{l}\text { Hyalomma } \\
\text { marginatum }\end{array}$ & 7 & 5 & 0 & 0 & 12 & $4.7 \%$ \\
\hline Total & 83 & 115 & 31 & 27 & 256 & \\
\hline
\end{tabular}

Date of sampling was a predictor of H. punctata IS (Fig. 5C); the only individual feature positively related to $H$. punctata IS in donkeys was the albino coat $(\mathrm{OR}=5.863,95 \% \mathrm{CI}$ $1.822-18.862 ; P<0.01)$. Despite the small number of infested donkeys, date of sampling and land cover type were significant predictors of Hy. marginatum IS in the final model after backward elimination.

\section{Discussion}

This study presents data on the species of adult ticks collected on donkeys living on Asinara island and their occurrence according to time, vegetation cover and site of sampling. Previous studies on the ixodofauna of the island showed that albino donkeys were infested by Hyalomma excavatum, R. bursa, Dermacentor marginatus (Ixodida: Ixodidae), H. punctata, Haemaphysalis otophyla and Rhipicephalus sanguineus (Garippa \& Sanna, 1990; Pinna et al., 1996). The current survey confirms the presence of H. punctata and R. bursa, but not the presence of the other ticks previously found. Furthermore, the donkeys sampled in 2015 were infested by Hy. marginatum, which has not been recorded previously in donkeys living on Asinara island.

Haemaphysalis punctata was the predominant species in Asinara's donkeys and was especially abundant in albino animals. Torina et al. (2006) recorded this tick in donkeys from Sicily, but at a lower frequency $(4.3 \%)$ than that found in donkeys on Asinara island (52.0\%). Records of this species on donkeys are scarce, but its presence on horses in central and southern Italy has been reported (Khoury et al., 1994).

Rhipicephalus bursa was the second most frequently found species on donkeys; it was also found in donkeys from Sicily (21.4\%) (Torina et al., 2006). Furthermore, in horses from Corsica, R. bursa had a moderate prevalence (21.1\%) (Grech-Angelini etal., 2016). Rhipicephalus bursa appeared to be a predominant species on domestic ruminants in other surveys carried out on the islands of Sardinia, Sicily and Corsica (Garippa etal., 1998; Torina etal., 2006; Grech-Angelini et al., 2016).

Hyalomma marginatum accounted for very few of the total collection of specimens; however, the study confirms the presence of feeding adults of Hy. marginatum on Asinara and demonstrates that the tick is able to complete its lifecycle on the 
Table 3. Risk factors associated with tick infestation levels in donkeys on Asinara island. Final models with ordinal logistic regression after backward elimination.

\begin{tabular}{|c|c|c|c|c|c|}
\hline Dependent variable & Independent variable & Factor & Odds ratio & $95 \% \mathrm{CI}$ & $P$-value \\
\hline \multirow[t]{5}{*}{ Overall tick infestation } & \multirow[t]{3}{*}{ Land cover type } & Grassland & 5.765 & $2.041-16.278$ & $<0.01 \dagger$ \\
\hline & & Mediterranean brushland & 2.605 & \multirow[t]{2}{*}{$1.088-6.241$} & \multirow{2}{*}{$<0.05^{*}$} \\
\hline & & Sparse vegetation (reference) & 1 & & \\
\hline & \multirow[t]{2}{*}{ Donkey coat } & Albino & 3.236 & \multirow[t]{2}{*}{$1.405-7.451$} & \multirow[t]{2}{*}{$<0.01 \dagger$} \\
\hline & & Coloured (reference) & 1 & & \\
\hline \multirow[t]{2}{*}{ Rhipicephalus bursa infestation } & Date of sampling & (continuous variable) & 0.999 & $0.999-0.999$ & $<0.001$ \\
\hline & Donkey age & (continuous variable) & 1.009 & $1.002-1.016$ & $<0.05^{*}$ \\
\hline \multirow[t]{3}{*}{ Haemaphysalis punctata infestation } & Date of sampling & (continuous variable) & 1.000 & $1.000-1.000$ & $<0.05^{*}$ \\
\hline & \multirow[t]{2}{*}{ Donkey coat } & Albino & 5.863 & \multirow[t]{2}{*}{$1.822-18.862$} & \multirow[t]{2}{*}{$<0.01 \dagger$} \\
\hline & & Coloured (reference) & 1 & & \\
\hline \multirow[t]{4}{*}{ Hyalomma marginatum infestation } & Date of sampling & (continuous variable) & 0.999 & $0.999-0.999$ & $<0.05^{*}$ \\
\hline & \multirow[t]{3}{*}{ Land cover type } & Grassland & 15.459 & $2.150-111.132$ & $<0.01 \dagger$ \\
\hline & & Mediterranean shrubland & 26.281 & \multirow{2}{*}{$0.905-763.522$} & \multirow[t]{2}{*}{0.057} \\
\hline & & Sparse vegetation (reference) & 1 & & \\
\hline
\end{tabular}

Significant at $* P<0.05 ; \dagger P<0.01 ; \ddagger P<0.001$.

$\mathrm{CI}$, confidence interval.

island. The immature stages of Hy. marginatum are parasites of small and medium-sized mammals and birds, whereas the adult stages primarily feed on ungulates. Findings of ticks on migratory birds suggest that Hy. marginatum could be introduced into new areas by avian hosts and that its survival may be influenced by climatic conditions. According to Estrada-Peña et al. (2015), the study area is included in the Mediterranean south climate domain, which represents suitable conditions for this tick. Hyalomma marginatum appears to be very common in Corsica (Grech-Angelini et al., 2016). It was also recovered in other Mediterranean islands with similar climatic conditions, such as Menorca, Sicily and Sardinia (Garippa et al., 1998; Castellà et al., 2001; Torina et al., 2006). On the island of Sardinia, the tick was previously observed at a higher prevalence on cattle (40\%) than on horses (16\%) (Deiana \& Arru, 1960). By contrast, other studies have confirmed that equids are suitable hosts for the tick; in Corsica, the proportion of Hy. marginatum obseryed on horses $(78 \%)$ was much higher than that found on cattle $(26 \%)$ (Grech-Angelini et al., 2016). Hyalomma marginatum was also reported as the most common tick species among Italian horses, although the overall prevalence of tick infestation was low (Lori etal., 2010).

The diversity of the tick species found on donkeys from Asinara also appears to be low in comparison with the findings of studies carried out in other areas; in Sicily, Torina et al. (2006) recorded six tick species and, more recently, Horak etal. (2017) found donkeys infested with eight tick species. Adults of the three species of tick identified on Asinara and on coloured donkeys in the current study usually feed on larger mammals, such as livestock and wild ungulates, and, according to Estrada-Peña et al. (2013), ruminants are suitable hosts for adult ticks of H. punctata, R. bursa and Hy. marginatum. A possible hypothesis that may explain the predominance of these ticks and the low species richness of ticks on donkeys in the present study concerns the dramatic reduction in the number of domestic ruminants on Asinara from 1998 onward, when the jail went out of use. At the end of 1987, when Asinara island

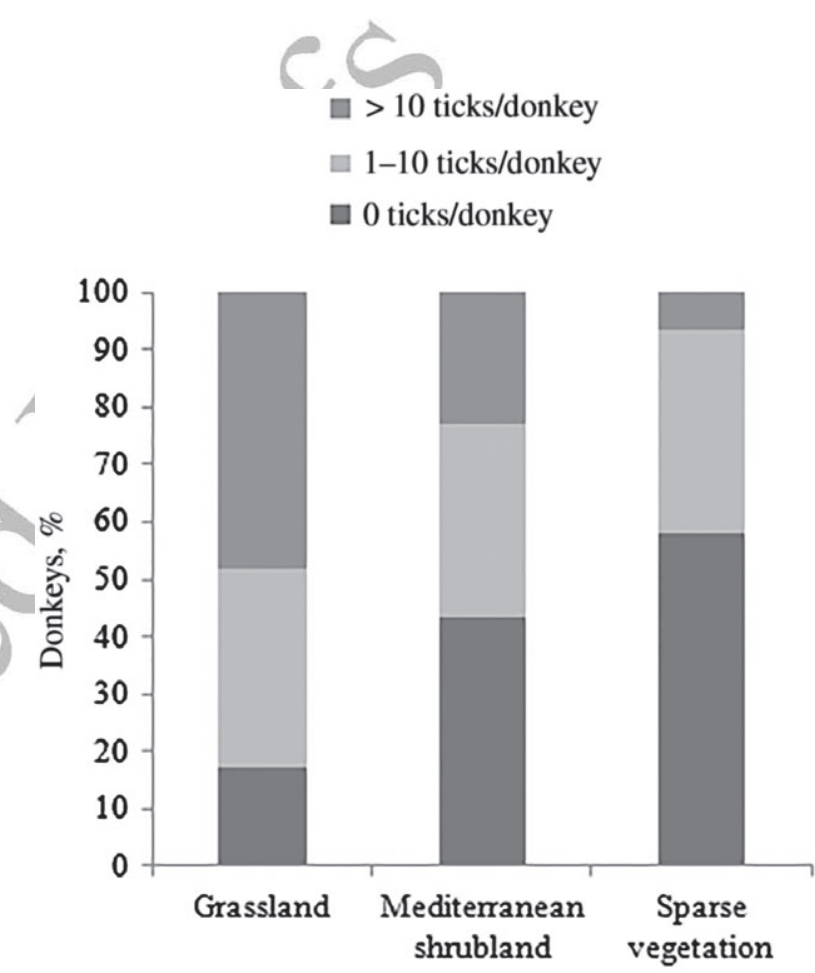

Fig. 3. Tick infestations in donkeys in Asinara National Park by vegetation coverage type.

was used as a prison, the numbers of ruminants amounted to 411 cattle, 1760 sheep and 1128 goats (G. Garippa, unpublished data, YEAR). At the time, horses $(n=130)$, pigs $(n=278)$ and unknown numbers of wild goats, mouflons and wild boars were also present. Currently, only a flock of almost 100 domestic goats grazes in a fenced pasture. However, wild goats, horses, mouflons and wild boars continue to roam freely on the island as in the past. In addition, as demonstrated by previous studies, two of the three species of tick (H. punctata and R. bursa) identified on Asinara donkeys usually prefer to feed on domestic ruminants 


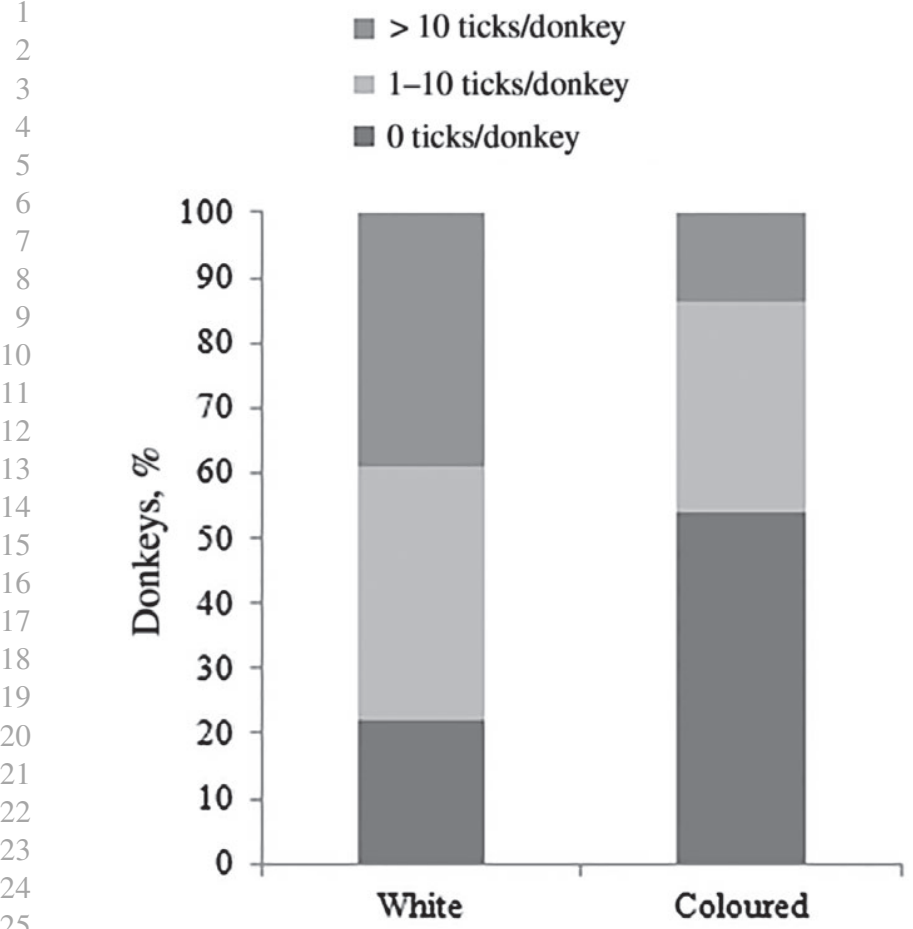

Fig. 4. Tick infestations in donkeys in Asinara National Park by colour of donkey.

rather than on equids (Psaroulaki et al., 2006; Torina et al., 2006; Sofizadeh et al., 2014). When the jail was in use, dogs and cats also lived on the island; at present, there are few domestic and sylvatic carnivores in Asinara National Park, which possibly contributes to the low acarological diversity in Asinara donkeys.

All of the ticks identified were restricted in range to the Mediterranean area, particularly to the biome 'Mediterranean forests, woodlands and scrub', and occurrences vary according to ecological region (Estrada-Peña et al., 2013). Given that in the study area, there were no donkeys grazing in forest or woodland, the highest occurrence of tick infestation in animals grazing in Mediterranean shrubland and grassland appears to be grossly in accordance with the findings of Estrada-Peña et al. (2013). The sparse vegetation is probably not suitable for free-living stages of ticks. Differences in tick occurrence may also be linked to life stage and host. In the present study, mainly adult ticks were recovered (77.3\%); larval and nymphal stages may be more strictly located in forests and the forest-scrub interface, which favours the presence of small mammals and birds. Moreover, decaying vegetation in the forest may provide higher levels of humidity which support the survival and moulting of immature stages, whereas more resistant adult questing ticks may reach more exposed areas in their efforts to find ungulate hosts.

Within the study period, date of sampling was not a significant predictor of overall tick infestation in Asinara donkeys. Thus, in this timeframe, the risk for tick bites seemed to be uniform in late spring/early summer and autumn; by contrast, in the final models for the three species of tick considered separately, date of sampling was always a significant predictor of IS. All H. punctata individuals of all stages were detected on donkeys in autumn; this is in accordance with other surveys on Mediterranean islands (Torina et al., 2006; Grech-Angelini et al., 2016). Hence, taking into account the seasonal dynamics of the various ticks, the lack of recording on equids in previous surveys may have depended on sampling carried out at times when the tick was not active (Psaroulaki et al., 2006; Sofizadeh etal., 2014). The opposite trend was observed for $R$. bursa and Hy. marginatum; both species were collected from donkeys mainly (R. bursa) or exclusively (Hy. marginatum) in late spring/early summer, similarly to collections reported by Torina et al. (2006), Sofizadeh et al. (2014) and Grech-Angelini et al. (2016).

With respect to risk factors for donkeys, albino donkeys were more highly infested than coloured donkeys. Albinism predisposes to skin diseases and ophthalmological problems: dermatitis and keratoconjunctivitis linked to photosensitivity have been described in Asinara albino donkeys. This may also result in a lower resistance to ectoparasitic infestation, as observed for myiasis cutanea (Pinna et al., 1996); moreover, low visual capacity causes albino donkeys to shelter from excessive light in the sunny hours and their prolonged presence near trees and shrubs may result in greater exposure to ticks in comparison with coloured animals.

With respect to the vectorial roles of ticks collected from donkeys on Asinara island, it should be noted that $H$. punctata is one of the most commonly reported species of this genus found on humans; it is confined to forest habitats in Europe and is mainly involved in the transmission of tick-borne encephalitis (TBE) virus, for which it is a competent vector. Apodemus flavicollis (Rodentia: Muridae) and Myodes glareolus (Rodentia: Cricetidae), the two species of rodent considered to represent the major reservoirs for the circulation of TBE virus in Central Europe, are not reported on the island and hence there should be no risk for TBE infection of humans within Asinara National Park. However, H. punctata is also a vector of Coxiella burneti (Legionellales: Coxiellaceae) and Rickettsia slovaca (Rickettsiales: Rickettsiaceae) (Estrada-Peña \& Jongejan, 1999).

Evidence of the presence of Hy. marginatum and $R$. bursa in the study area is of particular interest in view of the roles of these tick species in the transmission of, respectively, Theileria equi (Piroplasmida: Theileriidae) and Babesia caballi (Piropla: mida: Babesiidae), the agents of equine piroplasmosis (Roth. schild, 2013). Consequently, the exposure of Asinara donkes to these vectors poses a risk for infection with tick-borne disease (babesiosis, theileriosis) that may worsen their status as an endangered species. Although babesiosis and theileriosis in equids can be acute, subacute or chronic, piroplasmosis in endemic areas is frequently subclinical. Infected animals may remain carriers for long periods and act as sources of infection for other ticks. The poor management, inadequate veterinary care and poor nutrition common to equine populations living in natural and protected reserve areas may exacerbate the impacts of infection (Scoles \& Ueti, 2015).

Furthermore, the finding of Hy. marginatum is noteworthy as it is the competent vector and reservoir of Rickettsia aeschlimannii, a spotted fever rickettsia recently associated with human cases of Mediterranean spotted fever-like disease (Germanakis etal., 2013). High rates of infection by R. aeschlimannii have been found previously in Hyalomma ticks 

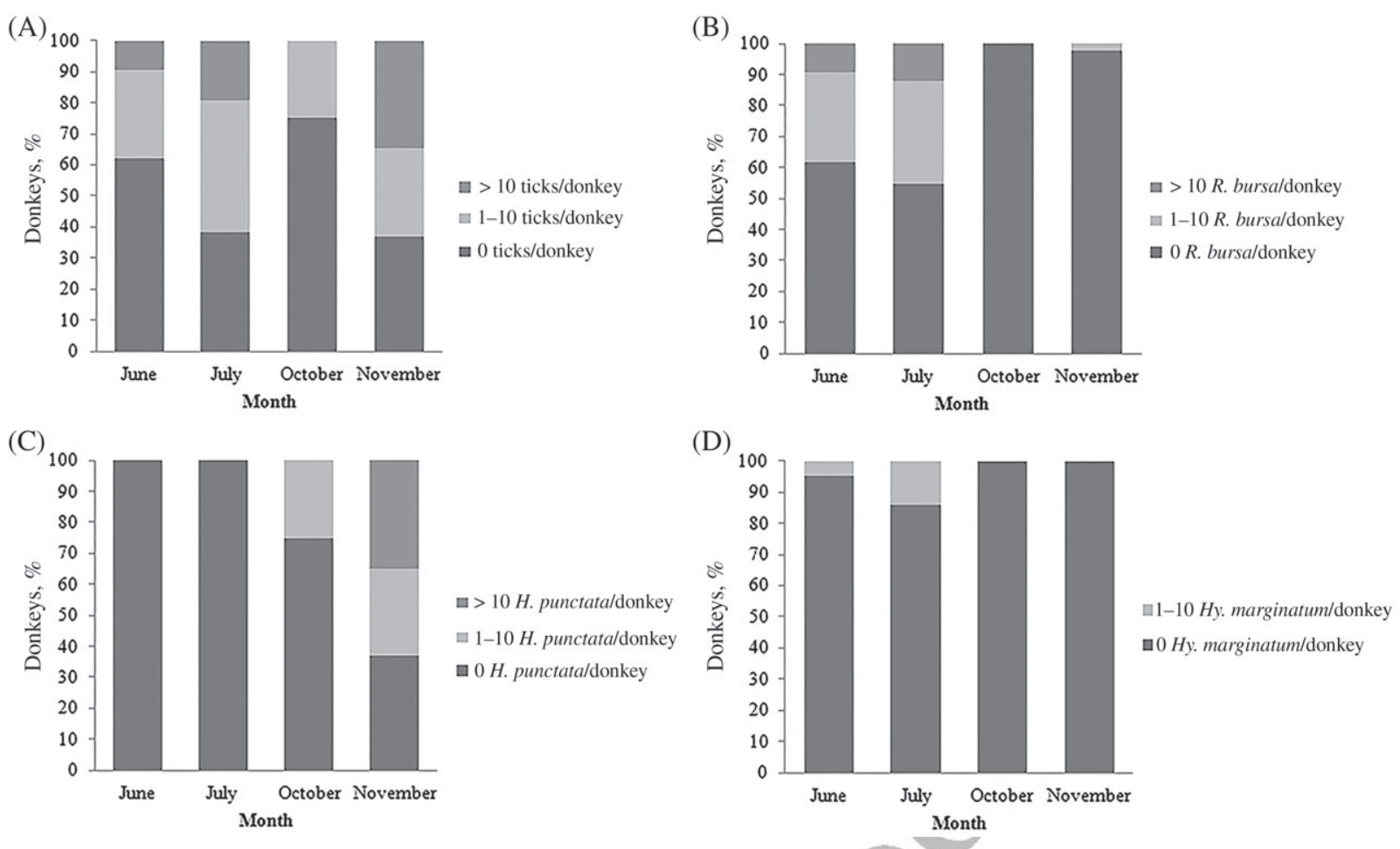

Fig. 5. Tick infestations in donkeys in Asinara National Park by month of sampling: (A) all ticks; (B) Rhipicephalus bursa; (C) Haemaphysalis punctata; (D) Hyalomma marginatum.

in Sardinia (Mura et al., 2008), Corsica (Matsumoto et al., 2004) and other Mediterranean regions (Beninati et al., 2005; Tomassone et al., 2013; Scarpulla etal., 2016). Hyalomma marginatum frequently bites humans, as described by Matsumoto et al. (2004). This suggests a potentially high risk for human exposure to rickettsia infection in Asinara National Park because the island is frequented by many visitors; moreover, the vector may also harbour several other pathogens (e.g. Crimean-Congo haemorrhagic fever virus, West Nile virus and Thogoto virus).

\section{Conclusions}

This study carried out in Asinara National Park showed that albino donkeys are more exposed to tick infestations than Sardinian coloured donkeys. The collected ticks included species involved in the transmission of pathogens to humans and, although further studies are required to exhaustively characterize the ixodofauna of the island, the data obtained in the present work show the risks to public health in the context of Asinara as an important tourist destination. Visitors engaged in tourism and outdoor recreational activities (trekking, bicycling and hiking) are at risk for exposure to tick bites and the transmission of pathogens (Colwell et al., 2011).

In summary, the data collected in the present study further emphasize that the preservation of natural reserves may create conditions favourable for tick survival; indeed, measures to protect wild fauna, combined with management practices designed to preserve the natural environmental, increase the ecological niches and proliferation of hosts crucial to the maintenance of both ticks and zoonotic pathogens (Estrada-Peña, 2009; Randolph, 2009). Thus, it is necessary to provide information on these issues to people visiting protected areas in order to prevent tick bites and related sanitary risks.

\section{Acknowledgements}

The authors would like to acknowledge Asinara National Park for logistical support during their field work.

The authors declare no conflicts of interest.

\section{References}

Beninati, T., Genchi, C., Torina, A., Caracappa, S., Bandi, C. \& Lo, N. (2005) Rickettsiae in ixodid ticks, Sicily. Emerging Infectious Diseases, 11, 509-511.

Castellà, J., Estrada-Peña, A., Almería, S., Ferrer, D., Gutiérrez, J. \& Ortuño, A. (2001) A survey of ticks (Acari: Ixodidae) on dairy cattle on the island of Menorca in Spain. Experimental and Applied Acarology, 25, 899-908.

Colwell, D.D., Dantas-Torres, F. \& Otranto, D. (2011) Vector-borne parasitic zoonoses: emerging scenarios and new perspectives. Veterinary Parasitology, 182, 14-21.

Deiana, S. \& Arru, E. (1960) Sulla riduzione dell'indice di mortalità negli erbivori della Sardegna per malattie protozoarie ematiche. Parassitologia, 2, 145-147.

Estrada-Peña, A. (2001) Distribution, abundance, and habitat preferences of Ixodes ricinus (Acari: Ixodidae) in northern Spain. Journal of Medical Entomology, 38, 361-370. 
Estrada-Peña, A. (2009) Tick-borne pathogens, transmission rates and climate change. Frontiers in Bioscience, 14, 2674-2687.

Estrada-Peña, A. \& Jongejan, F. (1999) Ticks feeding on humans: a review of records on human-biting Ixodoidea with special reference to pathogen transmission. Experimental and Applied Acarology, 23, $685-715$.

Estrada-Peña, A., Farkas, R., Jaenson, T.G.T. et al. (2013) Association of environmental traits with the geographic ranges of ticks (Acari: Ixodidae) of medical and veterinary importance in the western Palearctic. A digital data set. Experimental and Applied Acarology, 59, 351-366.

Estrada-Peña, A., de la Fuente, J., Latapia, T. \& Ortega, C. (2015) The impact of climate trends on a tick affecting public health: a retrospective modeling approach for Hyalomma marginatum (Ixodidae). PLoS One, 10, e0125760.

Garippa, G. \& Sanna, E. (1990) Ixodidi di frequente riscontro nei mammiferi dell'Asinara. Parassitologia, 32 (Suppl. 1), 117-118.

Garippa, G., Piazza, C., Biddau, M., Seu, W. \& Arru, E. (1998) Diffusion and distribution of ticks (Ixodidae) in the provinces of Sassari and Nuoro (Sardinia). Parassitologia, 40, 70.

Germanakis, A., Chochlakis, D., Angelakis, E., Tselentis, Y. \& Psaroulaki, A. (2013) Rickettsia aeschlimannii infection in a man, Greece. Emerging Infectious Diseases, 19, 1176-1177.

Grech-Angelini, S., Stachurski, F., Lancelot, R. et al. (2016) Ticks (Acari: Ixodidae) infesting cattle and some other domestic and wild hosts on the French Mediterranean island of Corsica. Parasites \& Vectors, 9, 582 .

Guglielmone, A.A., Robbins, R.G., Apanaskevich, D.A., Petney, T.N., Estrada-Peña, A. \& Horak, I.G. (2014) . The Hard Ticks of the World (Acari: Ixodida: Ixodidae). Springer, Dordrecht, Heidelberg, New York, NY, London.

Horak, I.G., Heyne, H., Halajian, A., Booysen, S. \& Smit, W.J. (2017) Parasites of domestic and wild animals in South Africa. L. Ixodid ticks infesting horses and donkeys. Onderstepoort Journal of Veterinary Research, 84, a1302.

Kugler, W., Grunenfelder, H.P. \& Broxham, E. (2008) Donkey breeds in Europe. Inventory, description, need for action, conservation. Report 2007/2008. Monitoring Institute for Rare Breeds and Seeds in Europe, St Gallen.

Lori, A., Gabrielli, S., Calderini, P. et al. (2010) Tick reservoirs for piroplasms in central and northern Italy. Veterinary Parasitology, $\mathbf{1 7 0}$, 291-296.

Manilla, G. (1998) . Acari Ixodidae, Fauna d'Italia. Edizioni Calderini, Bologna.

Matsumoto, K., Parola, P., Brouqui, P.\&. \& Raoult, D. (2004) Rickettsia aeschlimanni in Hyalomma ticks from Corsica. European Journal of Clinical Microbiology \& Infectious Diseases, 23, 732-734.
McCoy, K.D., Boulinier, T., Tirard, C. \& Michalakis, Y. (2001) Host specificity of a generalist parasite: genetic evidence of sympatric host races in the seabird tick Ixodes uriae. Journal of Evolutionary Biology, 14, 395-405.

Ministero delle Politiche Agricole, Alimentari e Forestali (2013) Linee guida per la conservazione e la caratterizzazione della biodiversità animale di interesse per l'agricoltura. Piano Nazionale sulla Biodiversità di Interesse Agricolo, Inea, Rome.

Mura, A., Masala, G., Tola, S. et al. (2008) First direct detection of rickettsial pathogens and a new rickettsia, 'Candidatus Rickettsia barbariae' in ticks from Sardinia, Italy. Clinical Microbiology and Infection, 14, 1028-1033.

Otranto, D., Torres, F.D., Giannelli, A. et al. (2014) Ticks infesting humans in Italy and associated pathogens. Parasites \& Vectors, 47, 328.

Pfäffle, M., Littwin, N., Muders, S.V. \& Petney, T.N. (2013) The ecology of tick-borne diseases. International Journal for Parasitology, 43, 1059-1077.

Pinna, W., Vacca, G.M., Cubeddu, G., Pintori, G. \& Garippa, G. (1996) Salvaguardia degli asinelli bianchi dell'Asinara: risultati di un intervento di controllo delle parassitosi. Ricerche di Biologia della Selvaggina, 24, 105-110.

Randolph, S.E. (2009) Perspectives on climate change impacts on infectious diseases. Ecology, 90, 927-931.

Rothschild, C.M. (2013) Equine piroplasmosis. Journal of Equine Veterinary Science, 33, 497-508.

Scarpulla, M., Barlozzari, G., Marcario, A., Salvato, L., Blanda, V. \& De Liberato, C. (2016) Molecular detection and characterization of spotted fever group rickettsiae in ticks from Central Italy. Ticks and Tick-borne Diseases, 7, 1052-1056.

Scherf, B.D. (2000) . World Watch List for Domestic Animal Diversity, 3rd edn. Food and Agriculture Organization of the United Nations, Rome.

Scoles, G. \& Ueti, M.W. (2015) Vector ecology of equine piroplasmosis. Annual Review of Entomology, 60, 561-580.

Sonenshine, D.E. (1993) - Biology of Ticks, 1st edn, Vol. 2. Oxford University Press, New York, NY.

Tomassone, L., Grego, E., Auricchio, D., Iori, A., Giannini, F. \& Rambozzi, L. (2013) Lyme borreliosis spirochetes and spotted fever group rickettsiae in ixodid ticks from Pianosa island Tuscany archipelago, Italy. Vector-Borne and Zoonotic Diseases, 13, 84-91.

Torina, A., Khoury, C., Caracappa, S. \& Maroli, M. (2006) Ticks infesting livestock on farms in Western Sicily, Italy. Experimental and Applied Acarology, 38, 75-86.

Accepted 5 November 2018 


\section{Graphical Abstract}

The contents of this page will be used as part of the graphical abstract of HTML only. It will not be published as part of main article.

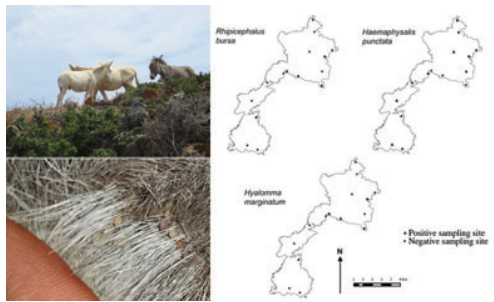

Sardinian coloured and albino donkeys are the most representative animals of Asinara National Park, which is visited yearly by thousands of tourists. Rhipicephalus bursa, Hyalomma marginatum and Haemaphysalis punctata were collected from donkeys on Asinara.

The tick species detected are competent vectors of several pathogens and thus pose a health risk to humans and animals. 